\title{
Experimental investigation on low-velocity impact response of wood skinned sandwich composites with different core configurations
}

DOI:

10.1016/j.mtcomm.2018.08.003

\section{Document Version}

Accepted author manuscript

Link to publication record in Manchester Research Explorer

Citation for published version (APA):

Demirciolu, T. K., Balkolu, F., nal, O., Arslan, N., Ay, \& Ata, A. (2018). Experimental investigation on low-velocity impact response of wood skinned sandwich composites with different core configurations. Materials Today Communications, 17, 31-39. https://doi.org/10.1016/j.mtcomm.2018.08.003

Published in:

Materials Today Communications

\section{Citing this paper}

Please note that where the full-text provided on Manchester Research Explorer is the Author Accepted Manuscript or Proof version this may differ from the final Published version. If citing, it is advised that you check and use the publisher's definitive version.

\section{General rights}

Copyright and moral rights for the publications made accessible in the Research Explorer are retained by the authors and/or other copyright owners and it is a condition of accessing publications that users recognise and abide by the legal requirements associated with these rights.

\section{Takedown policy}

If you believe that this document breaches copyright please refer to the University of Manchester's Takedown Procedures [http://man.ac.uk/04Y6Bo] or contact uml.scholarlycommunications@manchester.ac.uk providing relevant details, so we can investigate your claim.

\section{OPEN ACCESS}




\title{
EXPERIMENTAL INVESTIGATION ON LOW-VELOCITY IMPACT RESPONSE OF WOOD SKINNED SANDWICH COMPOSITES WITH DIFFERENT CORE CONFIGURATIONS
}

\author{
T. K. Demircioğlu' ${ }^{1}$, F. Balıkoğlu' ${ }^{1}$, O. İnal ${ }^{1}$, N. Arslan², İ. Ay ${ }^{1}$ A. Ataş ${ }^{\text {* }}$ \\ ${ }^{1}$ Department of Mechanical Engineering, Balikesir University, Balikesir, 10145, Turkey \\ ${ }^{2}$ Department of Energy Systems Engineering, Manisa Celal Bayar University, \\ Manisa, Turkey
}

\begin{abstract}
In this paper, an experimental investigation on the low-velocity impact response of wood skinned hybrid sandwich composites was presented. Several alternative design configurations were developed by using rubber-cork and E-glass composite layers between the foam core and wood skin in order to improve the impact performance of conventional sandwich composites. Low-velocity impact (LVI) testing was performed using a drop weight test machine at different impact energies and destructive cross-sectioning was performed to examine the interior damage growth and penetration depth of the specimens. The impact performance of the specimens was evaluated in terms of energy absorption capacity, maximum contact force and penetration depth. The multi-core design concept significantly improved the energy absorption capacity with a reduced extent of impact induced damage. The proportion of recyclable materials in each configuration and the energy absorption level per unit cost were also presented for the interest of product designers.
\end{abstract}

Keywords: Wood skin; Sandwich structures; Impact behaviour; Damage.

\footnotetext{
* Corresponding author: a.atas@ balikesir.edu.tr ( Tel: +90 266 6121194),

Department of Mechanical Engineering, Balikesir University, Balikesir, 10145, Turkey
} 


\section{Introduction}

Recyclable and sustainable materials in structural applications are becoming increasingly popular due to the strict environmental and legislative restrictions. Although fibre reinforced plastic (FRP) sheet materials have been extensively used to develop advanced sandwich structures in order to maximise the specific bending rigidity and strength, they are relatively unsustainable as a result of difficulties in recycling processes. Thus, renewable materials like woods are emerging as a possible alternative to non-renewable materials [1-3]. For instance, wood-based eco-structures are widely used for meeting the requirements of marine, automotive and environmental-friendly building applications [4, 5]. For marine applications as an example, wood based sandwich structures are mainly used as components of the decks, partitions or elements for ceilings and floor structures [6]. In addition to conventional sandwich configurations, an effective combination of different foam, wood and cork materials have been used as skin and core materials, aiming at superior properties such as low density, good thermal and acoustic insulation [7-12].

During service life, sandwich structures experience low velocity impact loadings such as tool drop during manufacturing or maintenance, moorings or floating objects, ice floes and debris [13]. It is generally accepted that low-velocity impacts (LVI) occur at velocities below 10 $\mathrm{m} / \mathrm{s}$, and can reduce the strength of whole structure under quasi-static and dynamic loads due to the localised internal skin and/or core damage $[14,15]$.

It was shown that the increased core density and the skin thickness improves the LVI damage resistance of foam core sandwich composites [16-19]. As an alternative, hybrid sandwich structure concepts have been introduced in order to increase the LVI resistance with intermediate layers strategically placed between the face sheets and the core material [20]. It 
was observed that introducing ductile intermediate layers beneath external skins in foam core sandwiches improved protection against core crushing under LVI loadings [21-24]. On the other hand, using a stiffer composite sheet into a traditional single sandwich structure decreased the local effect of the impact energy and so it was spread in a wider area within the structure $[25,26]$. Experimental results indicated that an increased damage resistance may be obtained as a function of the mechanical properties of the intermediate layers and their location [21-26].

Eco-friendly structures receive increasing attention due to their environmental benefits such as recyclability and sustainability. Despite their popularity, they have intrinsically lower mechanical properties which have to be complemented with synthetic materials to form stronger hybrid structures. Wood materials are relatively brittle and absorb lower specific energy $\left(\mathrm{J} / \mathrm{kgm}^{2}\right)$ under LVI loadings $[13,27]$. For instance, balsa wood cores perform well under static loading, but they fail catastrophically under impact loading due to the low fracture toughness along the grain direction [28]. With regard to plywood structures, at high impact energy levels, they are perforated with heavy loss of structural integrity, which can be undesirable in most applications [29]. Previous studies also revealed that the impact damage tolerance of such wood-based materials can be increased by using them in conjunction with composite skins in sandwich designs [29-31]. Shin et al. [30] showed that the energy absorption of wood-based sandwich structures was comparable with the aluminium honeycomb sandwich structures. Susainathan J. et al. [29] observed that glass fibre-skinned sandwich structures with plywood cores exhibited comparable energy absorption capabilities and lower indentation in comparison to reference material, which made of Nomex honeycomb core and carbon or glass reinforced skins. It was stated that the recyclability of these new 
designs is questionable. In our earlier work [31], ashwood was found to be stronger against the impact loading in comparison to pinewood when used as intermediate layers in classical sandwich structures.

Despite the wealth of research efforts on the LVI response of conventional sandwich panels, novel structural sandwich designs require detailed experimental characterisation under given sets of design constraints. Motivated by the current trend towards the bio-composites, new sandwich composites containing synthetic PVC foam core with natural-based layers were manufactured in the present work. By employing a compressible intermediate layer and a stiffer composite internal sheet, it was aimed to enhance the LVI performance of woodskinned sandwich composites. The effects of rubber-cork layer thickness and foam core material on the impact resistance and damage mechanisms of the wood-skinned sandwich composites were characterised by load-displacement curves, energy absorption rates, contact forces and penetration depths. The characteristics of the impact damage mechanisms were analysed by the cross-sectional images of the impacted specimens.

\section{Experimental study}

\subsection{Materials and manufacturing method}

Heat-treated ashwood (thermowood) was chosen as face sheets (skin) whereas rubber cork was used as the intermediate layer between the ashwood skin and the foam core to absorb the LVI energy and minimise the excessive local foam crushing under the impact point. Rubber cork layers are generally applied for flooring applications due to their good impact absorption capability, $100 \%$ recyclability and ease of maintenance [32-34]. 
The wood skinned sandwich composite panels were manufactured by the hand lay-up technique. $5 \mathrm{~mm}$ thick heat-treated ashwood (Thermo Wood $\left.{ }^{\circledR}\right)$ material with a density of 650 $\mathrm{kg} / \mathrm{m}^{3}$ was used as the face sheet material for all panels whereas low and high density PVC foams were used as core materials which were denoted as LPVC and HPVC, respectively. Table 1 summarizes the physical and mechanical properties of the PVC foams obtained from the manufacturer's datasheet [35]. The effective mechanical properties of the ashwood material were measured according to the DIN standards and are given in Table 2.

Five specimens were tested for both compressive and bending tests. The ashwood specimens with dimensions of $25 \mathrm{~mm} \times 50 \mathrm{~mm} \times 500 \mathrm{~mm}$ (thickness $\times$ width $\times$ span length) were tested under three-point bending according to DIN EN 310 [36] standard. The dimensions of the compression test specimens were $60 \mathrm{~mm} \times 20 \mathrm{~mm} \times 20 \mathrm{~mm}$ (parallel to grain direction) according to DIN EN 52185 [37] standard.

Several design combinations of sandwich structures were developed with different foam thicknesses and alternating foam type locations with respect to the impacted face in addition to rubber-cork sheets which were placed between the ashwood skins and the foam cores. The properties of the rubber-cork material are given in Table 3 [38]. Figure 1 (a) shows the baseline wood skinned single foam sandwich (SFS) design where only the $25 \mathrm{~mm}$ and $15 \mathrm{~mm}$ thick HPVC foams were sandwiched between the ashwood skins. The SFS specimens with rubber-cork intermediate layers under the ashwood skins were introduced as the second design as shown in Fig. 1 (b) and were referred to as SFSR specimens. In the third design, wood skinned multi-foam layered sandwich (abbreviated as MFSR) concepts were formed by introducing a $1 \mathrm{~mm}$ thick internal composite sheet between two PVC foam core layers, see Fig. 1 (c). The internal composite sheet was made of [0/90] E-glass biaxial non-crimp fabric 
reinforcement with an areal density of $600 \mathrm{~g} / \mathrm{m}^{2}$ and vinyl ester resin matrix material (see Table 4). The in-plane mechanical properties of internal sheet were determined with coupon tests following the ISO and ASTM test standards [39-41]. The PVC foams together with the internal composite sheet were considered as a separate unit and produced by a wet layup process while these foam core units were joined to the ashwood skins and rubber-cork layers by using a polyurethane solvent-based one component adhesive. After a total curing time of $24 \mathrm{~h}$, the sandwich panels were cut into $100 \mathrm{~mm} \times 100 \mathrm{~mm}$ square specimens for impact tests. The manufacturing matrix of eight different sandwich specimen designs is listed in Table 5.

\subsection{Drop weight impact test}

The sandwich specimens were subjected to low-velocity impact test by using Instron CEAST Fractovis Plus-7526 drop weight testing machine. It consists of a drop-weight tower, an impactor, a velocity sensor, a data acquisition system and an anti-rebound system to prevent multiple impacts on the specimen for an individual test. Impact loading was applied by a hemispherical steel impactor of $12.7 \mathrm{~mm}$ tip diameter and $5 \mathrm{~kg}$ total mass at the centre of the specimens, which were clamped by a pneumatic fixture with a $76.2 \mathrm{~mm}$ hole diameter as shown in Fig. 2. In accordance with the ASTM D3763 standard [42], the clamped sandwich specimens were impacted with impact energy levels ranging from $15 \mathrm{~J}$ to $75 \mathrm{~J}$ at room temperature. The test velocities for $15,30,45$, and $75 \mathrm{~J}$ impact energy levels were 2.468, 3.49, 4.275, and $5.518 \mathrm{~m} / \mathrm{s}$, respectively. Three specimens were tested for each sandwich configuration and average values were calculated. In order to obtain the impact response of the specimens and to reach quantitative conclusions, various parameters such as contact force, 
impactor displacement, and absorbed energy values were recorded by a data acquisition system during the impact event which are detailed in the following sections.

\section{Experimental results and discussion}

A load-displacement curve in an impact test contains significant information about the damage process [43]. The displacement term in this study is defined as the distance that impactor travels following the time of impact. Load-displacement curves comprising of ascending and descending sections can be divided into two main categories as open and closed curves [43-45]. Depending on the impact energy level, the descending section may represent rebounding, penetration and perforation cases. If the descending section is completely a softening curve, the load-displacement curve may be an open curve in that the impactor penetrates into the specimen or even perforates the specimen [45].

Figures 3-11 illustrate the selected representative load-displacement graphs and crosssectional images of impacted specimens for each sandwich configuration. Considering the thickness differences of the specimens, penetration depths and penetration depth to total thickness ratio of the specimens are given in Fig. 12 (a-b).

The absorbed energy during an impact test was calculated by integrating the area under the load-displacement curve. This energy was absorbed by the sandwich specimen through the perforation of the skin as well as the crushing and failure process of the foam core [46]. The energy absorption is normalised by the total weight of the sandwich specimens to take into account the additional layers and the different densities of the foam core materials. Figures 12 (c) and (d) summarise the absorbed energy and the specific energy absorption of the sandwich specimens for complete perforation case. The maximum contact forces of all the sandwich 
specimens subjected to different impact energies are summarised in Fig. 12 (e). The absorbed energy to cost ratio were calculated by dividing the absorbed energy to the unit areal cost of each configuration as seen in Fig. 12 (f). The unit areal cost was calculated by summing up the cost of each individual constituent used per $\mathrm{m}^{2}$ of the laminate. Since the geometry of the ashwood skin was kept constant in all sandwich specimens, its cost was not included into the calculation of unit areal cost.

\subsection{Single foam core sandwich (SFS) design with ashwood skin}

Figures 3 (a) and 4 (a) show the load-displacement plots of H25 and H15 specimens, respectively. The impact response of SFS structure is a typical example of that associated with low-velocity impact on sandwich structures, where two distinct peak points due to the upper and lower skin penetrations are clear in the load-displacement plots. In contrast to laminates, the graphs showing a mountain-like shape with two peaks are obtained when the penetration and/or perforation thresholds are exceeded in single-core sandwich structures [19, 43, 47]. Between these peaks (except for the $15 \mathrm{~J}$ where only the top skin was penetrated), there is a region where the force forms a plateau, which attributed to the displacement of the impactor through the foam core. The initial and secondary peak force values for these specimens were close due to perforation of the same material used for top and bottom skins. Top ashwood skin failure and core cracking were observed at impact energy of $15 \mathrm{~J}$ in both specimens. The penetration depths were almost the same (Fig 12a). However, the penetration depth to specimen thickness ratio was $48 \%$ in $\mathrm{H} 15$ specimen due to the lower thickness of the HPVC foam core while it was $34.3 \%$ for $\mathrm{H} 25$ specimen (Fig 12b). 
As the impact energy was increased to $30 \mathrm{~J}$, the secondary peak was observed in the plots, indicating the partial perforation of the bottom ashwood skin of $\mathrm{H} 25$ and complete perforation of the H15 as seen in Figs. 3 and 4.

$\mathrm{H} 25$ specimens were completely perforated at the impact energy of $45 \mathrm{~J}$. It can be seen from the load-displacement curves that $\mathrm{H} 25$ specimen exhibited a prolonged plateau region at impact energy of $45 \mathrm{~J}$. The longer plateau results in higher energy absorption as seen in Fig 12 (c) and was related to the interaction of the impactor through the relatively thicker foam core in H25 compared to H15 specimens for the perforation case. Such results have been observed in previous studies $[47,48]$. The authors reported that with increasing the core thickness, the penetration can occur at a wider energy range under LVI loadings [48]. Also, it was observed that as the core thickness increased, specimens showed more elastic behaviour and so, the maximum contact force decreased while contact time and maximum deflection values were increasing. Comparing the samples H15 and H25 at 30 Joule energy level, the decrease in core thickness increased the maximum contact force as observed in Figure 12e. Similar results were obtained with different core structures, for instance in sandwich containing balsa wood core, the increase in core thickness causes an increase in the perforation threshold [47].

Although the H25 specimen was heavier, it absorbed higher specific energy than the H15 specimen. Similar results were observed in another study [49]. Authors found that the increase in the foam core thickness could improve the specific energy absorption amount of the same skinned sandwich composite under an impact event.

\subsection{Single foam core sandwich design with rubber-cork intermediate layer and ashwood skin (SFSR)}


Figures 5-7 illustrate the load-displacement plots and cross-sectional images of SFSR specimens. At $15 \mathrm{~J}$ of impact energy, the rubber cork layer had an insignificant effect on the penetration depth. However, the deformation capability of the rubber cork layer prevented the impactor to reach the foam core, meaning a lesser damage to the core material. As illustrated in Fig. 12 b, the penetration depth to thickness ratio was also slightly reduced from $34.3 \%$ to $30.8 \%$ with the introduction of the rubber cork layers in H25-R2 specimen. This reduction was from $48 \%$ to $41.4 \%$ in H15-R2 specimen. A comparison between the H15-R2 and H15R5 specimens shows that the penetration depth to thickness ratio was reduced from $41.4 \%$ to

\section{$34.3 \%$ due to thicker rubber cork.}

When the impact energy was increased to $30 \mathrm{~J}$, SFSR specimens did not exhibit the second peak except the H15-R2 specimen. The penetration depth of H25-R2 and H15-R2 specimens was decreased in comparison to $\mathrm{H} 25$ and $\mathrm{H} 15$ specimens, respectively. Also, the penetration depth to thickness ratios were decreased about $20 \%$ compared to the SFS counterparts. Compared H25-R2 with H25, this reduction was observed from $97.1 \%$ to $76.9 \%$. H15-R2 specimen showed a penetration depth to thickness ratio of $75.9 \%$ while H15 was completely perforated at 30J energy level. H15-R5 specimens with the thicker rubber cork exhibited higher penetration depth in comparison to the H15-R2 specimens (see in Fig. 12a). The penetration depth to thickness ratio was almost the same due to increased thickness of the sandwich panel. This may be attributed to low stiffness of the rubber cork material.

All of the SFSR specimens were completely perforated at $45 \mathrm{~J}$ impact loading. The comparison of Fig. 4 (a) and Fig. 6 (a) shows that H15-R2 specimen exhibits higher impact resistance than the H15 specimen. The same trend was also observed between the H25-R2 
and $\mathrm{H} 25$ specimens. This suggests that the $2 \mathrm{~mm}$ thick rubber-cork layer increased the perforation threshold within the energy intervals used in the present study. Similarly, increasing the rubber-cork thickness increased the absorbed energy but decreased the specific absorbed energy due to the increased weight. Compared to the reference sample [48], the absorbed energy values in the SFSR specimens are comparable and higher but the SFS values are low. The improvement provided by the intermediate layer can be seen in Figure 12c.

\subsection{Multi foam core sandwich design with E-glass internal sheet, rubber-cork intermediate layer and ashwood skin (MFSR)}

The load-displacement plots of MFSR specimens are given in Figs. 8-11. In order to evaluate the effect of alternative HPVC and LPVC foam core arrangements while the laminated composite sheet remains at the same location, tests were performed for four different design cases as tabulated in Table 5. These specimens were subjected to impact energies of 15, 45 and $75 \mathrm{~J}$. As expected, the load- displacement curves are significantly different than those of SFS and SFSR designs due to the presence of the laminated composite sheet.

At $15 \mathrm{~J}$ of impact energy, the impactor perforated the ashwood skin in all four types of specimens with some differences. HH-R2 and HL-R2 type specimens, which have the HPVC at the impacted region, were subjected to core crushing while LL-R2 and LH-R2 specimens with the LPVC at the impacted region were suffered a significant core cracking. It can be said that the density of the foam material in the direction of impact at low energy levels affects the damage state. At the 15J energy level, HH-R2 and HL-R2 showed a penetration depth to 
thickness ratio of $30.8 \%$ while it was $35.9 \%$ for LL-R2 and LH-R2 specimens (see in Fig. 12 b).

In the case of $45 \mathrm{~J}$ of impact energy, the impactor contacts with the E-glass internal sheet and reveals a force peak in the load-displacement curves (see Figs. 8 to 11). This interaction caused a fibre breakage and inter-laminar delamination in the E-glass sheet. Although the impactor did not get into contact with the lower core, it was crushed due to the load transferred through the internal sheet. The delamination width were determined by measuring over the damaged specimens by a vernier caliper. It is also seen from the Figures 8-9 that the extent of delamination are was reduced by introducing HPVC foam core foam on the sides of the internal sheet (Fig. 8b). The higher deformation capability of LPVC foam caused a larger delamination area due to stiffness incompatibility (Fig. 9b). At 45J energy level, the delamination width at LL-R2 specimen was about $60 \mathrm{~mm}$ while it was around $40 \mathrm{~mm}$ at $\mathrm{HH}$ R2 specimen. In the HL-R2 and LH-R2 specimens, the internal sheet was broken at this energy level (Figs. 10b, 11b). At this energy level, the LL-R2 samples showed a $69.2 \%$ penetration depth to thickness value, while the others remained at the same level of $64.1 \%$ (see, Fig. 12b).

For the impact energy of $75 \mathrm{~J}$, all curves are in an open form corresponding to a full perforation case in which all the ashwood skins, internal composite sheet and the core material were perforated. At this energy level, it is clear that the first, second and third peaks represent failure in the upper ashwood skin, internal composite sheet and lower ashwood skin, respectively. LL-R2 specimens experienced the lowest energy absorption because of the low density PVC core material. In contrast, HH-R2 comprising of the high density PVC resulted highest absorbed energy (see Fig. 12 (c)). This confirms the earlier result, which indicates that 
stiffer foam core material in the entire thickness of the core reduces the impact induced damage of multilayered sandwich panels $[25,26]$. Compared the absorbed energy values of HL-R2 and LH-R2, placing the higher density foam uppermost resulted in a slight increase in the perforation resistance (see in Figs. 12c). Such results were observed in the impact response of the graded foam sandwich constructions [50]. The cross-sectional views of the MFSR specimens revealed that using a high density PVC foam core created a more impactresistant structure under LVI loading.

\section{Conclusions}

Industrial woods inherently fail in a brittle manner which makes them susceptible to impact loadings. Despite this weakness, they are considered as eco-friendly materials due to their recyclability and alternative structural configurations have been evaluated in order to increase their impact resistance.

In the present paper, innovative, eco-friendly and impact resistant sandwich structure designs were developed using recyclable and long-lasting thermowood and rubber-cork materials. Three different concepts were presented in order to evaluate their performance under low velocity impact loading. Cross-sectional images of the damaged specimens enabled visual inspection of interior damage patterns and penetration depth values. As a result, this research shed light on the LVI behavior of environmentally friendly wood-skinned sandwich composites. The results can be used to improve the LVI damage tolerance of commercial available PVC core wood marine sandwich panels. Fundamental findings are summarised below: 
- The absorbed energy values were obtained from the test data and represent the area under the load-displacement graphs. For the $15 \mathrm{~J}$ of impact energy, the upper skin was perforated and absorbed $34.8 \%$ of the impact energy while $59.2 \%$ of that was absorbed by the foam core and/or the rubber cork damage depending on the structure. At $12 \mathrm{~mm}$ final penetration, $94 \%$ of impact energy was absorbed and $6 \%$ was spent as rebounding case.

- Introduction of the rubber cork intermediate layer resulted in reduced penetration depth for $30 \mathrm{~J}$ of impact energy by increasing the energy absorption. At low level of impact energy, the rubber cork prevented foam cracking, and the damage was therefore confined to the recyclable materials only. This is an advantage for the repair processes and to avoid the progressive cracking of the foam upon further loading cycles.

- Penetration depth was increased with increasing the rubber cork thickness due to the replacement of stiff foam core by a relatively flexible rubber cork material on the travel path of the impactor. However, the absorbed energy was increased about $10 \%$ while the specific absorbed energy decreased due to weight gain of the sandwich structure.

- The maximum contact force values were between 1.5 and $2 \mathrm{kN}$ for SFS and SFSR structures. In MFSR structures it was raised up to $4.5 \mathrm{kN}$ due to introduction of high stiffness E-glass internal composite layer. The higher contact force was resulted in higher perforation threshold and absorbed energy. For the non-perforating energy levels, high density foam core at the impacted side of the MFSR design may be used to considerably lighten the structure. 
- From the economical perspective of view, with respect to the specific absorbed energy and absorbed energy/cost ratios, HH-R2 was found to be the best panel configuration among the proposed design alternatives.

- The introduction of the rubber-cork material increased the recyclability rate of the sandwich structures up to 57\%. In the MFSR configurations, the recyclability rate is $35.6 \%$.

The proposed wood skinned sandwich composite designs are easy to manufacture, repair and recycle in addition to their valuable esthetical appearance. These configurations may be utilised in floor applications such as decks and cabins, bulkhead panels as well as interior and exterior design applications.

\section{Acknowledgements}

The authors are grateful to Dr Okan Özdemir and Professor Ramazan Karakuzu of Dokuz Eylül University for useful discussions.

\section{References}

[1] M. Matos, M. Simplicio, Innovation and sustainability in mechanical design through materials selection, Materials \& design 27(1) (2006) 74-78.

[2] M.a.D. Bovea, R. Vidal, Materials selection for sustainable product design: a case study of wood based furniture eco-design, Materials \& design 25(2) (2004) 111-116.

[3] S.J. Pickering, Recycling technologies for thermoset composite materials - current status, Composites Part A: Applied Science and Manufacturing 37(8) (2006) 1206-1215.

[4] V. Bucci, P. Corigliano, V. Crupi, G. Epasto, E. Guglielmino, A. Marinò, Experimental investigation on Iroko wood used in shipbuilding, Proceedings of the Institution of Mechanical Engineers, Part C: Journal of Mechanical Engineering Science 231(1) (2017) 128-139.

[5] S. Abrate, B. Castanié, Y.D. Rajapakse, Dynamic failure of composite and sandwich structures, Springer Science \& Business Media2012.

[6] F. Negro, C. Cremonini, R. Zanuttini, M. Properzi, F. Pichelin, A new wood-based lightweight composite for boatbuilding, Wood Research 56(2) (2011) 257-66. 
[7] C. Cremonini, F. Negro, M. Properzi, R. Zanuttini, Wood-based composites in marine craft: The state of the art in Italy, COST E49 conference: Lightweight wood-base composites. Production, properties and usage, Bled, 23rd-25th June, 2008, pp. 15-33.

[8] J. Susainathan, F. Eyma, E. De Luycker, A. Cantarel, B. Castanie, Manufacturing and quasi-static bending behavior of wood-based sandwich structures, Composite Structures 182 (2017) 487-504.

[9] N. Lakreb, B. Bezzazi, H. Pereira, Mechanical behavior of multilayered sandwich panels of wood veneer and a core of cork agglomerates, Materials \& Design (1980-2015) 65 (2015) 627-636.

[10] N. Lakreb, S. Knapic, J.S. Machado, B. Bezzazi, H. Pereira, Properties of multilayered sandwich panels with an agglomerated cork core for interior applications in buildings, European Journal of Wood and Wood Products (2017) 1-11.

[11] Y. Qi, H. Fang, H. Shi, W. Liu, Y. Qi, Y. Bai, Bending performance of GFRP-wood sandwich beams with lattice-web reinforcement in flatwise and sidewise directions, Construction and Building Materials 156 (2017) 532-545.

[12] F. Zhang, W. Liu, L. Wang, Y. Qi, D. Zhou, H. Fang, Flexural behavior of hybrid composite beams with a bamboo layer and lattice ribs, Journal of reinforced plastics and composites 34(7) (2015) 521-533.

[13] L. Sutherland, A review of impact testing on marine composite materials: Part I-Marine impacts on marine composites, Composite Structures 188 (2017) 197-208.

[14] L. Sutherland, A review of impact testing on marine composite materials, Part III: Damage tolerance and durability, Composite Structures 188 (2018) 512-518.

[15] S. Abrate, Impact engineering of composite structures, Springer Science \& Business Media2011.

[16] M.A. Hazizan, W. Cantwell, The low velocity impact response of foam-based sandwich structures, Composites Part B: Engineering 33(3) (2002) 193-204.

[17] T. Anderson, E. Madenci, Experimental investigation of low-velocity impact characteristics of sandwich composites, Composite Structures 50(3) (2000) 239-247.

[18] J. Wang, A.M. Waas, H. Wang, Experimental and numerical study on the low-velocity impact behavior of foam-core sandwich panels, Composite Structures 96 (2013) 298-311.

[19] C. Atas, U. Potoğlu, The effect of face-sheet thickness on low-velocity impact response of sandwich composites with foam cores, Journal of Sandwich Structures \& Materials 18(2) (2016) 215-228.

[20] A. Mamalis, K. Spentzas, N. Pantelelis, D. Manolakos, M. Ioannidis, A new hybrid concept for sandwich structures, Composite Structures 83(4) (2008) 335-340.

[21] A.P. Suvorov, G.J. Dvorak, Enhancement of low velocity impact damage resistance of sandwich plates, International Journal of Solids and Structures 42(8) (2005) 2323-2344.

[22] G.J. Dvorak, A.P. Suvorov, Protection of sandwich plates from low-velocity impact, Journal of composite materials 40(15) (2006) 1317-1331.

[23] S.A. Sabah, A. Kueh, M. Al-Fasih, Bio-inspired vs. conventional sandwich beams: A low-velocity repeated impact behavior exploration, Construction and Building Materials 169 (2018) 193-204.

[24] S.A. Sabah, A. Kueh, M. Al-Fasih, Comparative low-velocity impact behavior of bio-inspired and conventional sandwich composite beams, Composites Science and Technology 149 (2017) 64-74.

[25] S. Jedari Salami, M. Sadighi, M. Shakeri, M. Moeinfar, An investigation on low velocity impact response of multilayer sandwich composite structures, The Scientific World Journal 2013 (2013).

[26] D. Jiang, D. Shu, Local displacement of core in two-layer sandwich composite structures subjected to low velocity impact, Composite Structures 71(1) (2005) 53-60.

[27] M. Hildebrand, Local impact strength of various boat-building materials, Technical Research Centre of Finland1997.

[28] I. Daniel, J. Abot, P. Schubel, J.-J. Luo, Response and damage tolerance of composite sandwich structures under low velocity impact, Experimental mechanics 52(1) (2012) 37-47.

[29] J. Susainathan, F. Eyma, E. De Luycker, A. Cantarel, B. Castanie, Experimental investigation of impact behavior of wood-based sandwich structures, Composites Part A: Applied Science and Manufacturing (2018).

[30] K.B. Shin, J.Y. Lee, S.H. Cho, An experimental study of low-velocity impact responses of sandwich panels for Korean low floor bus, Composite Structures 84(3) (2008) 228-240.

[31] F. Balıkoğlu, T. Demircioğlu, O. İnal, N. Arslan, A. Ataş, Compression after low velocity impact tests of marine sandwich composites: Effect of intermediate wooden layers, Composite Structures 183 (2018) 636-642.

[32] L. Gil, Cork composites: a review, Materials 2(3) (2009) 776-789.

[33] S. Knapic, V. Oliveira, J.S. Machado, H. Pereira, Cork as a building material: a review, European Journal of Wood and Wood Products 74(6) (2016) 775-791. 
[34] O. Castro, J.M. Silva, T. Devezas, A. Silva, L. Gil, Cork agglomerates as an ideal core material in lightweight structures, Materials \& Design 31(1) (2010) 425-432.

[35] Datasheet for Airex C70 PVC Foam. http://www.airexbaltekbanova.com/airex-c70-pvc-foam.html. (Accessed 15.01.2018.

[36] DIN, EN 310-Wood-based panels; determination of modulus of elasticity in bending and of bending strength, German Institute for Standardization, Burggrafenstr. 6, 10787 Berlin, 1993.

[37] DIN, 52185-Testing of wood; compression test parallel to grain, German Institute for Standardization, Burggrafenstr. 6, 10787 Berlin, 1976.

[38] Datasheet for Teknofoam Rubber-cork. http://www.teknofoam.com.tr/tekno-cork.html. (Accessed 15.01.2018.

[39] ISO, Plastics - ISO 527-1-determination of tensile properties - part 1: General principles, International Standard, 2012.

[40] ASTM, D7078 / D7078M, Standard Test Method for Shear Properties of Composite Materials by VNotched Rail Shear Method, ASTM International, West Conshohocken, PA, Pennsylvania, USA, 2012.

[41] ASTM, D 6641/D 6641 M-09 Standard Test Method for Determining the Compressive Properties of Polymer Matrix Composites Laminates Using a Combined Loading Compression (CLC) Test Fixture, ASTM International, West Conshohocken, Pennsylvania, USA, 2009.

[42] ASTM, D3763-15, Standard Test Method for High Speed Puncture Properties of Plastics Using Load and Displacement Sensors, ASTM International, West Conshohocken, PA, Pennsylvania, USA, 2015.

[43] C. Atas, C. Sevim, On the impact response of sandwich composites with cores of balsa wood and PVC foam, Composite Structures 93(1) (2010) 40-48.

[44] C. Atas, O. Sayman, An overall view on impact response of woven fabric composite plates, Composite Structures 82(3) (2008) 336-345.

[45] C. Atas, Y. Akgun, O. Dagdelen, B.M. Icten, M. Sarikanat, An experimental investigation on the low velocity impact response of composite plates repaired by VARIM and hand lay-up processes, Composite Structures 93(3) (2011) 1178-1186.

[46] A.K.J. Al-Shamary, R. Karakuzu, O. Özdemir, Low-velocity impact response of sandwich composites with different foam core configurations, Journal of Sandwich Structures \& Materials 18(6) (2016) 754-768.

[47] O. Ozdemir, N. Oztoprak, H. Kandas, Single and repeated impact behaviors of bio-sandwich structures consisting of thermoplastic face sheets and different balsa core thicknesses, Composites Part B: Engineering 149 (2018) 49-57.

[48] O. Ozdemir, R. Karakuzu, A.K.J. Al-Shamary, Core-thickness effect on the impact response of sandwich composites with poly (vinyl chloride) and poly (ethylene terephthalate) foam cores, Journal of Composite Materials 49(11) (2015) 1315-1329.

[49] S.B. Loganathan, H.K. Shivanand, Effect of Core Thickness and Core Density on Low Velocity Impact Behavior of Sandwich Panels with PU Foam Core, Journal of Minerals and Materials Characterization and Engineering 3(03) (2015) 164.

[50] J. Zhou, Z. Guan, W. Cantwell, The impact response of graded foam sandwich structures, Composite Structures 97 (2013) 370-377. 


\section{Figure Captions}

Figure 1 Schematic drawings of (a) wood skinned sandwich (SFS), (b) SF with rubber-cork intermediate layers (SFSR) and (c) multilayered wood skinned sandwich (MFSR) design concepts

Figure 2 Schematic view of the impact test setup

Figure 3 a) Load versus displacement curves and b) cross-sectional damage view of H25

Figure 4 a) Load versus displacement curves and b) cross-sectional damage view of H15

Figure 5 a) Load versus displacement curves and b) cross-sectional damage view of H25-R2

Figure 6 a) Load versus displacement curves and b) cross-sectional damage view of H15-R2

Figure 7 a) Load versus displacement curves and b) cross-sectional damage view of H15-R5

Figure 8 a) Load versus displacement curves and b) cross-sectional damage view of HH-R2

Figure 9 a) Load versus displacement curves and b) cross-sectional damage view of LL-R2

Figure 10 a) Load versus displacement curves and b) cross-sectional damage view of HL-R2

Figure 11 a) Load versus displacement curves and b) cross-sectional damage view of LH-R2

Figure 12 LVI test results; a) penetration depth, b) penetration depth/specimen thickness, c) absorbed energy, d) specific absorbed energy, e) maximum contact force and f) absorbed energy/cost 
Table 1: Properties of PVC foam cores [35].

\begin{tabular}{cccccccccc}
\hline Code & Trademark & $\begin{array}{c}\text { Density } \\
\left(\mathbf{k g} / \mathbf{m}^{\mathbf{3}}\right)\end{array}$ & $\begin{array}{c}\text { Compressive } \\
\text { Strength } \\
(\mathbf{M P a})\end{array}$ & $\begin{array}{c}\text { Compressive } \\
\text { Modulus } \\
(\mathbf{M P a})\end{array}$ & $\begin{array}{c}\text { Tensile } \\
\text { Strength } \\
(\mathbf{M P a})\end{array}$ & $\begin{array}{c}\text { Tensile } \\
\text { Modulus } \\
(\mathbf{M P a})\end{array}$ & $\begin{array}{c}\text { Shear } \\
\text { Strength } \\
(\mathbf{M P a})\end{array}$ & $\begin{array}{c}\text { Shear } \\
\text { Modulus } \\
(\mathbf{M P a})\end{array}$ & Color \\
\hline LPVC & $\begin{array}{c}\text { Airex } \\
\text { C70.55 }\end{array}$ & 60 & 0,9 & 69 & 1,3 & 45 & 0,85 & 22 & Yellow \\
\hline HPVC & $\begin{array}{c}\text { Airex } \\
\text { C70.75 }\end{array}$ & 80 & 1,45 & 104 & 2 & 66 & 1,2 & 30 & Green \\
\hline
\end{tabular}


Table 2: Properties of ashwood skin material

\begin{tabular}{ccccccc}
\hline Material & Trademark & $\begin{array}{c}\text { Density } \\
\left(\mathbf{k g} / \mathbf{m}^{\mathbf{3}}\right)\end{array}$ & $\begin{array}{c}\text { Compressive } \\
\text { Strength, } \\
\text { parallel to grain } \\
(\mathbf{M P a})\end{array}$ & $\begin{array}{c}\text { Flexural strength, } \\
\text { longitudinal to grain } \\
\text { direction } \\
(\mathbf{M P a})\end{array}$ & $\begin{array}{c}\text { Flexural } \\
\text { Modulus } \\
(\mathbf{M P a})\end{array}$ & $\begin{array}{c}\text { Moisture } \\
\text { content } \\
(\%)\end{array}$ \\
\hline Ashwood & Novawood & 650 & 69.3 & 90.7 & 13300 & $4-6$ \\
\hline
\end{tabular}


Table 3: Properties of rubber-cork intermediate sheet [38].

\begin{tabular}{cccccc}
\hline Material & Trademark & Density $\left(\mathbf{k g} / \mathbf{m}^{3}\right)$ & $\begin{array}{c}\text { Tensile Strength } \\
(\mathbf{M P a})\end{array}$ & $\begin{array}{c}\text { Compressibility } \\
(\boldsymbol{\%})\end{array}$ & Hardness \\
\hline \multirow{2}{*}{ Rubber-cork } & TeknoCork & $100-110$ & 0.52 & $25-40$ & 75 Shore A \\
\hline
\end{tabular}


Table 4: In plane properties of E-glass/vinyl ester internal composite sheet

\begin{tabular}{lc}
\hline Material properties & Values \\
\hline Moduli & \\
\hline Longitudinal Young's modulus $(\mathrm{GPa})$ & 20.3 \\
\hline Transverse Young's modulus $(\mathrm{GPa})$ & 19.2 \\
\hline Poisson's ratio & 0.16 \\
\hline In-plane shear modulus $(\mathrm{GPa})$ & 3.4 \\
\hline Strengths & 312 \\
\hline Longitudinal tensile strength $(\mathrm{MPa})$ & 112 \\
\hline Longitudinal compressive strength $(\mathrm{MPa})$ & 43.3 \\
\hline Laminate shear strength $(\mathrm{MPa})$ &
\end{tabular}


Table 5: Manufacturing matrix of specimens

\begin{tabular}{|c|c|c|c|c|c|c|c|c|c|c|c|c|}
\hline 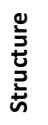 & $\begin{array}{l}\text { Specimen } \\
\text { Code }\end{array}$ & Skin & $\begin{array}{l}\text { Intermediate } \\
\text { Layer }\end{array}$ & & CORE & & $\begin{array}{l}\text { Intermediate } \\
\text { Layer }\end{array}$ & Skin & $\begin{array}{c}\text { Thickness } \\
\text { (mm) }\end{array}$ & $\begin{array}{c}\text { Specimen } \\
\text { weight } \\
\text { (gr) }\end{array}$ & $\begin{array}{c}\text { Recyclable } \\
\text { content } \\
\text { (Vol. \%) }\end{array}$ & $\begin{array}{c}\text { Cost } \\
\left(€ / \mathrm{m}^{2}\right)\end{array}$ \\
\hline \multirow{2}{*}{ 岀 } & $\mathrm{H} 25$ & AW & --- & --- & HPVC25 & --- & --- & AW & 35 & 73 & 28.6 & 137 \\
\hline & $\mathrm{H} 15$ & $\mathrm{AW}$ & --- & --- & HPVC15 & --- & --- & AW & 25 & 67 & 40 & 86 \\
\hline \multirow{3}{*}{$\begin{array}{l}\text { जे } \\
\text { 㟧 }\end{array}$} & H25R2 & AW & R2 & --- & HPVC25 & --- & $\mathrm{R} 2$ & AW & 39 & 94 & 35.9 & 141 \\
\hline & H15R2 & $\mathrm{AW}$ & R2 & --- & HPVC15 & --- & $\mathrm{R} 2$ & AW & 29 & 88 & 48.3 & 90 \\
\hline & H15R5 & AW & R5 & --- & HPVC15 & --- & R5 & AW & 35 & 127 & 57.1 & 95 \\
\hline \multirow{3}{*}{ 喜 } & HHR2 & AW & $\mathrm{R} 2$ & HPVC12 & E-GLASS & HPVC12 & $\mathrm{R} 2$ & AW & 39 & 134 & 35.9 & 157 \\
\hline & LLR2 & $\mathrm{AW}$ & $\mathrm{R} 2$ & LPVC12 & E-GLASS & LPVC12 & $\mathrm{R} 2$ & AW & 39 & 126 & 35.9 & 143 \\
\hline & $\begin{array}{l}\text { LHR2 } \\
\text { HLR2 }\end{array}$ & AW & R2 & LPVC12 & E-GLASS & HPVC12 & $\mathrm{R} 2$ & AW & 39 & 130 & 35.9 & 150 \\
\hline 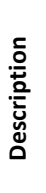 & $\begin{array}{l}\text { SFS: Single } \\
\text { MFSR: Mul } \\
\text { AW: Ashwo } \\
\text { HPVC25: } 25 \\
\text { HPVC12: } 12 \\
\text { Cost }(€ / \mathrm{m} 2\end{array}$ & $\begin{array}{l}\text { oam co } \\
\text { foam c } \\
\text { d, R2: } \\
\text { mm PV } \\
\text { mm PV } \\
\text { It inclu }\end{array}$ & $\begin{array}{l}\text { sandwich desig } \\
\text { e sandwich des } \\
\mathrm{mm} \text { Rubber Cor } \\
80 \mathrm{~kg} / \mathrm{m}^{3} \text { AIREX } \\
80 \mathrm{~kg} / \mathrm{m}^{3} \text { AIREX } \\
\text { es the total cost }\end{array}$ & $\begin{array}{l}\text { vith ash w } \\
\text { with E-gl } \\
\text { R5: } 5 \mathrm{~mm} \\
0.75 \text { (Gree } \\
0.75 \text { (Gree } \\
\text { f all layers }\end{array}$ & $\begin{array}{l}\text { skin, SFSR } \\
\text { sheet, rubb } \\
\text { ber Cork, E } \\
\text { HPVC15: } 15 \\
\text { LPVC12: } 12 \\
\text { ept ashwoc }\end{array}$ & $\begin{array}{l}\text { igle foam } \\
\text { cork intern } \\
\text { ASS: } 600 \mathrm{~g} \\
\text { m PVC } 80 \mathrm{k} \\
\text { n PVC } 60 \mathrm{k} \\
\text { kins. }\end{array}$ & $\begin{array}{l}\text { sandwich desi } \\
\text { iate layer and a } \\
\mathrm{T}^{2} \text { bi-axial fabric } \\
\mathrm{n}^{3} \text { AIREX C70.75 } \\
7^{3} \text { AIREX C70.55 }\end{array}$ & $\begin{array}{l}\text { with r } \\
\text { wood s } \\
\text { (jreen) } \\
\text { ellow) }\end{array}$ & $\begin{array}{l}\text { ber-cork int } \\
\text { in, }\end{array}$ & mediate lay & nd ashwood & \\
\hline
\end{tabular}

